\title{
Outstanding performance of an invasive alien tree Bischofia javanica relative to native tree species and implications for management of insular primary forests
}

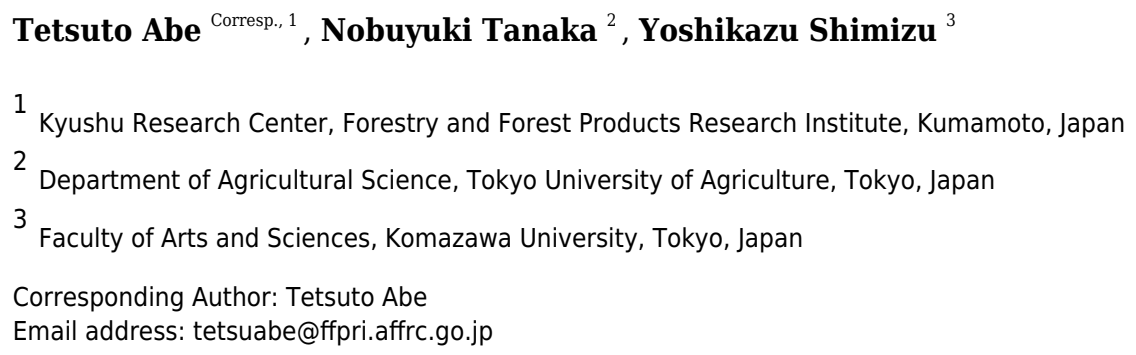

Invasive alien tree species can exert severe impacts, especially in insular biodiversity hotspots, but have been inadequately studied. Knowledge of the life history and population trends of an invasive alien tree species is essential for appropriate ecosystem management. The invasive tree Bischofia javanica has overwhelmed native trees on Hahajima Island in the Ogasawara Islands, Japan. We explored forest community dynamics 2 years after a typhoon damaged the Sekimon primary forests on Haha-jima Island, and predicted the rate of population increase of $B$. javanica using a logistic model from forest dynamics data for 19 years. During the 2 years after the typhoon, only $B$. javanica increased in population size, whereas populations of native tree species decreased. Stem diameter growth of $B$. javanica was more rapid than that of other tree species, including native pioneer trees. Among the understory stems below canopy trees of other species, $B$. javanica grew most rapidly and $B$. javanica canopy trees decreased growth of the dominant native Ardisia sieboldii. These competitive advantages were indicated to be the main mechanism by which $B$. javanica replaces native trees. The logistic model predicted that $B$. javanica would reach 30\% of the total basal area between 2017 (in the eastern plot adjacent to a former $B$. javanica plantation) and 2057 (in the western plot distant from the plantation site), which is a maximum percentage allowing to eradicate under the present guideline of the National Forest. The results suggest immediate removal of $B$. javanica is required to preserve native biodiversity in these forests. 
1 Outstanding performance of an invasive alien tree Bischofia javanica relative to native tree species and

2 implications for management of insular primary forests

3

4 Tetsuto Abe ${ }^{1, *}$, Nobuyuki Tanaka ${ }^{2}$, Yoshikazu Shimizu ${ }^{3}$

5

6

$7 \quad{ }^{1}$ Kyushu Research Center, Forestry and Forest Products Research Institute

$8 \quad{ }^{2}$ Department of Agricultural Science, Tokyo University of Agriculture

$9 \quad{ }^{3}$ Faculty of Arts and Sciences, Komazawa University

$10 *$ Author for correspondence: Tetsuto Abe, Kyushu Research Center, Forestry and Forest Products Research

11 Institute, Kurokami 4-11-16, Chuo-ku, Kumamoto 860-0862, Japan. tetsuabe@ffpri.affrc.co.jp

12 Tel. +81-96-343-3730, Fax +81-96-344-5054

13 


\section{Abstract}

Invasive alien tree species can exert severe impacts, especially in insular biodiversity hotspots, but

have been inadequately studied. Knowledge of the life history and population trends of an invasive alien tree species is essential for appropriate ecosystem management. The invasive tree Bischofia javanica has overwhelmed native trees on Haha-jima Island in the Ogasawara Islands, Japan. We explored forest community dynamics 2 years after a typhoon damaged the Sekimon primary forests on Haha-jima Island, and predicted the rate of population increase of $B$. javanica using a logistic model from forest dynamics data for 19 years. During the 2 years after the typhoon, only B. javanica increased in population size, whereas populations of native tree species decreased. Stem diameter growth of B. javanica was more rapid than that of other tree species, including native pioneer trees. Among the understory stems below canopy trees of other species, B. javanica grew most rapidly and B. javanica canopy trees decreased growth of the dominant native Ardisia sieboldii. These competitive advantages were indicated to be the main mechanism by which $B$. javanica replaces native trees. The logistic model predicted that B. javanica would reach 30\% of the total basal area between 2017 (in the eastern plot adjacent to a former B. javanica plantation) and 2057 (in the western plot distant from the plantation site), which is a maximum percentage allowing to eradicate under the present guideline of the National Forest.

The results suggest immediate removal of $B$. javanica is required to preserve native biodiversity in these forests.

31 Keywords forest dynamics, diameter growth rate, logistic model, oceanic island, tree invasions, typhoon disturbance 


\section{Introduction}

2000; Mack et al. 2000; Lockwood et al. 2007; Bellard et al. 2016). Invasive trees have a competitive advantage

due to their fast growth rate (Lamarque et al. 2011) and act as ecosystem engineers by altering biological interactions, water runoff, litter quality, and nutrient cycling (Vitousek and Walker 1989; Binggeli 1996; Fleischmann 1997; Crooks 2002; Lepš et al. 2002; Wiser et al. 2002; Meyer and Lavergne 2004; Gaertner et al. 2014; Motard et al. 2015). Such impacts on native ecosystems are amplified on oceanic islands owing to an inherent vulnerability to alien species (D'Antonio and Dudley 1995; Lonsdale 1999; Sax et al. 2002; Pyšek and Richardson 2006; Kier et al. 2009; Walsh et al. 2012). As examples of the serious consequences of an invasive tree species, Miconia calvescens attracts seed dispersers, shows high shade tolerance, and threatens native plant biodiversity in Pacific insular mesic forests (Meyer and Florence 1996; Medeiros et al. 1997). The alien nitrogen fixer Morella faya changes nutrient cycling and alters development of the forest vegetation on Hawaiian volcanic lava flows (Vitousek and Walker 1989). On Réunion Island, Casuarina equisetifolia disturbs primary succession on lava flows (Potgieter et al. 2014) and Ligustrum robustum subsp. walkeri can become the dominant woody species in natural forests on this island (Lavergne et al. 1999). Despite many examples of their ecological impacts, research on invasive trees has not progressed sufficiently (Richardson et al. 2014), probably because of the long lifespan of trees, which leads to a long time-lag between the initial invasion and expansion in distribution

(Webster et al. 2005; Wangen and Webster 2006).

Peer] reviewing PDF | (2020:03:47293:1:1:NEW 16 Jun 2020) 

gap formation, shade-tolerant alien trees sometimes spread under the closed canopy of a mature native forest since the initial colonization of the island (Mueller-Dombois 2008). Given that ecosystem degradation generally progresses as alien species invade, a conservation plan should take into account the invasion rate. However, few case studies have estimated the rate of invasion from stand dynamics data (Webster et al. 2005). Additional tree species are causing drastic changes to the vegetation (Hata et al. 2006; Fukasawa et al. 2009; Abe et al. 
mode between shade and direct sunlight (Yamashita et al. 2000). Such flexibility helps individuals to outcompete

native trees after a disturbance event. The distribution of B. javanica on Haha-jima Island overlaps with that of

mesic forests in which several endemic species are aggregated and thus poses a serious threat to the native

ecosystem. In contrast, the forests in the Sekimon area of Haha-jima have experienced minimal anthropogenic

disturbance and thus still resemble the original primary mesic forests (Shimizu 2003; Abe et al. 2018).

life history and population trend should be clarified (Sakai et al. 2001). We employed a permanent plot census,

which is a standard method to describe forest dynamics (Losos and Leight 2004), and explored the dynamics of

trees focusing on the relationships between alien and native species. Generally, the ecological risks posed by

(Frappier et al. 2003). Management of invasive alien species must be strategic to reduce the high social costs

(Higgs et al. 2000; Pimentel et al. 2000). These observations suggest that appropriate prediction of the expansion

of invasive tree species will contribute to effective forest management. In this study, we first investigated the 


\section{Methods}

90

91

92

93

94

\section{Study site}

The oceanic Ogasawara Islands are located in a subtropical region of the Pacific Ocean (between $24^{\circ} 14^{\prime} \mathrm{N}$ and $27^{\circ} 44^{\prime} \mathrm{N}$, and $140^{\circ} 52^{\prime} \mathrm{E}$ and $142^{\circ} 16^{\prime} \mathrm{E}$ ). The resident biota contains a high percentage of endemic species (Shimizu 2003). Haha-jima Island is one of the two inhabited islands in the archipelago. It covers $20 \mathrm{~km}^{2}$ and has a maximum elevation of $463 \mathrm{~m}$ above sea level. The island's central mountains are covered by mesic forests that consist of relatively tall trees (about $15 \mathrm{~m}$ in height) compared with that of other forests in the Ogasawara Islands. The Sekimon mesic forests cover uplifted limestone in the northeastern corner of Haha-jima. The uplifted limestone has a doline-like central depression. Relatively thick sedimentary soil (Okamoto et al., 1995) and protection from wind by the walls of the doline have favored the growth of dense, tall forest on the base of the doline. This environment provides habitat for many plant species that the distributions are restricted to the Sekimon (Abe et al. 2018). B. javanica was introduced to the Ogasawara Islands for the silvicultural purpose before 1905 (Toyoshima 1938; Shimizu 2003). Although there is no record of planting B. javanica in the Sekimon in the forest management ledger, a participator attested that B. javanica had been planted before 1935 (Toyoda 2003). In 1997, the seaward edge of the doline collapsed (Fig. 1a) and, subsequently, many trees have been exposed to salt-bearing onshore wind, causing desiccation and salt damage to the trees. 
106 September in the northwestern Pacific $\left(20.3^{\circ} \mathrm{N}, 159.2^{\circ} \mathrm{E}\right)$, about $1800 \mathrm{~km}$ southeast of the Ogasawara Islands.

107 The typhoon was closest to Haha-jima Island on 22 and 23 September when it passed about $100 \mathrm{~km}$ west of

108 Haha-jima. At that time, the atmospheric pressure decreased to $930 \mathrm{hPa}$, the maximum wind velocity attained

$10945 \mathrm{~m} \mathrm{~s}^{-1}$, and the $170 \mathrm{~km}$ radius of storm area experienced a wind velocity $\geq 25 \mathrm{~m} \mathrm{~s}^{-1}$ estimated by the Dvorak

110 method (Japan Meteological Agency, 2019).

111

112 Field survey

We selected a survey area in the central portion of the primary forests in the Sekimon area and

established two 2-ha census plots $(100 \mathrm{~m} \times 200 \mathrm{~m})$ because there is a steep limestone ridge difficult to traverse

115 between the two plots. We surveyed all trees with diameter at breast height (DBH) $\geq 10 \mathrm{~cm}$ in 2006 and described

116 the status of each individual's crown in terms of whether it formed part of the forest canopy or understory. We

117 defined canopy trees as individuals in which more than half of the crown surface was exposed to direct sunlight

118 (i.e., not shaded by neighboring trees); for individuals classified as an understory tree, we recorded the tree

119 species that covered the largest proportion of its crown. This judgement was conducted by eyesight, aided by

observation using binoculars when necessary. In 2008, we conducted a second census following the same method

of the first census. The abbreviations shown in Table 1 were used for the species names used in the figures and

tables in this paper. 
124

125

126

127

128

southern portion of this plot disappeared in a landslide in 1997 (Fig. 1a). The present study plot included the remaining portion $(60 \mathrm{~m} \times 50 \mathrm{~m})$ of the Shimizu plot in the southeastern part of the western plot. Our reconstruction of the Shimizu plot was based on a tree-by-tree map drawn in 1987 (Shimizu 1994). We checked the position of characteristic large trees (e.g., Melia azedarach) and old stumps of Morus boninensis that had been cut about 130 years previously but had not decomposed because of the strong, decay-resistant wood (Yoshida and Oka 2000). The 1987 data enabled us to analyze changes in species composition in terms of the number of stems and basal area. However, we could not analyze individual mortality and growth since 1987 because Shimizu (1994) did not label individual trees.

To detect the impacts of typhoon 0614 YAGI, we surveyed the damage soon after the first tree census (November and December 2006). We recorded the types of damage for individual trees with $\mathrm{DBH} \geq 10 \mathrm{~cm}$ in the northern half of the western plot ( $1 \mathrm{ha}, N=2675)$. The damage to each tree was classified as defoliated, snapped, uprooted, or trapped (under one or more uprooted trees). Among these damaged trees, the stems that died at the 2008 survey were judged to have died due to typhoon damage, and the mortality rate was defined as the number of the dead stems in 2008 divided by the number of stems in 2006 damage survey. Field survey was approved for the Ogasawara National Park by the Ministry of Environment (No. 0606328007, No.080507006) and for the Ogasawara National Forest by the Forest Agency (No.18-2-50 and No.20-1-32). 


\section{Statistical analyses}

We evaluated the annual diameter growth rate in 2-year period as ((DBH in 2008)-(DBH in

2006) $) /($ survey interval months)*12/(DBH in 2006)*100 for each tree species. The morality rate of each tree

species was defined as the number of dead stems in the 2008 survey divided by the number of stems in 2006

( $\mathrm{N}$ in 2006$) /(\mathrm{N}$ in 2006$) * 100$, where $\mathrm{N}$ is the number of stems. Generally, trees have a trade-off relationship

Hahajima Island seemed to have good performance for both. To confirm this, the Pearson's product-moment

when all tree species were used and when only B. javanica was removed. the number of dead stems as a responsible variable and the tree species as a responsible variable, respectively. 
160 analysis: the effect of the canopy tree species on a given understory species and the growth differences among

161 the understory tree species under a given canopy species. Both analyses used a general linear model (GLM) with

162 a Gaussian link function and a multiple-comparison test using R. The responsible variable was the annual

163 diameter growth rate of understory tree stems in both GLM analyses. The explanatory variable was understory

164 tree species in the comparison among understory species under a given canopy species and was canopy tree

165 species in the comparison among canopy species over a given understory species.

to the fast growth. Even if individual understory stems are likely to die sooner or later, there are always many

to index the crown area $(\mathrm{CW})$ of each tree species:

$$
\mathrm{CW}=\mathrm{NS} / \mathrm{NC}
$$
stems of the species.

\section{Prediction of increase in B. javanica occupancy}


178 dynamics of an invasive tree species (e.g. Buckley et al. 2003). However, we could not use such a model in the

179 present analysis because we surveyed the young trees less than $10 \mathrm{~cm}$ in DBH including seedlings only once

180 (Abe et al., 2018). Instead, we used a simple logistic curve (Radosevich et al. 2003; Webster and Wangen 2009) to predict future population growth of B. javanica in terms of the number of stems and basal area. Given that it can be assumed that the spread of an invasive tree species is random and continuous within the forest, a simple model prediction is considered to be sufficiently practicable (Frappier et al. 2003). The model represented the proportion of B. javanica $\left(D_{\mathrm{BJ}}\right)$ with an upper limit of 1.0 for the proportion, as follows: both plots is considered to be homogeneous. Accordingly, we applied these parameters to the prediction of $B$. javanica dynamics in both plots. 
196

197

198

199

200

201

202

203

204

205

206

207

208

209

210

211

212

213

resembles a $B$. javanica forest stand with more than $40 \%$ occupancy of the total basal area (Shimizu 1988). In

addition, as a property of the logistic model, the estimated year tends to include a smaller error in the central portion of the logistic curve (e.g., between $30 \%$ and $70 \%$ occupancy) than that at each extreme (i.e., the first year of invasion and the end of the simulation period). Therefore, forecast years reaching $30 \%$ and $50 \%$ occupancy are expected to be most accurate and robust.

\section{Results}

\section{Survival, growth, and typhoon damage}

Typhoon 0614 YAGI was situated closest to Haha-jima Island on 22 and 23 September 2006. The typhoon defoliated all standing stems (Fig. 1b), and snapped, uprooted, and trapped trees accounted for 7.1\%, $2.7 \%$, and $0.2 \%$ of the total, respectively (Table 2). There was no significant difference in the proportion of stems of these types of typhoon damage among native species from Bischofia javanica. Pioneer trees (sun-lit trees growing rapidly in the early stage of succession or in the gaps) exhibited relatively high mortality (Zanthoxylum ailanthoides var. inerme at 16.7\%, Trema orientalis at 33.3\%, and Cyathea mertensiana at 21.4\%), as did some later-successional species (Ochrosia nakaiana at 50.0\% and Psychotria homalosperma at 21.4\%). B. javanica showed low mortality (1.9\%) in response to the typhoon disturbance.

The number of stems decreased between 2006 and 2008 among the most frequent tree species (more 
214 result of recruitment of 44 individuals to the $\mathrm{DBH} \geq 10 \mathrm{~cm}$ size class and the death of 10 individuals. Species

215 that showed the greatest decrease in number of stems were an endemic pioneer, Z. ailanthoides var. inerme

$216(-43.3 \%)$, and an endemic tree fern, Cyathea mertensiana $(-34.8 \%)$. The proportion of the number of

217 recruitments into the stem size class $\mathrm{DBH} \geq 10 \mathrm{~cm}$ was largest for the alien species $B$. javanica (8.8\%) followed

218 by Callicarpa subpubescens (6.9\%) and Ficus boninsimae (6.6\%). Some native species had a significantly higher

219 proportion of the number of dead stems and significantly less proportion of the number of recruitments than $B$.

220 javanica (Fig. 2). Annual diameter growth rate (Fig. 3) was largest in B. javanica $(3.1 \pm 0.1 \%$, mean \pm SE)

221 followed by three pioneers, C. mertensiana $(2.1 \pm 0.4 \%), Z$. ailanthoides var. inerme $(2.1 \pm 0.3 \%)$, and $C$.

222 subpubescens $(2.0 \pm 0.3 \%)$. The diameter growth rates of dominant native species were less than half that of $B$.

223 javanica (e.g., Ardisia sieboldii at $0.8 \pm 0.0 \%$, Elaeocarpus photiniifolius at $1.0 \pm 0.1 \%$, and Pisonia umbellifera

224 at $1.3 \pm 0.1 \%$ ). Annual diameter growth rate was negatively correlated with population growth rate when the

225

226

227

228

229

230

231 data for B. javanica were omitted from those for the most frequent tree species (Pearson's product-moment correlation, $r=-0.635, t=-3.182, \mathrm{df}=15, p=0.006)$, but no significant relationship was observed when the data for B. javanica were included $(r=-0.225, t=-0.922, \mathrm{df}=16, p=0.370)$.

\section{Effects of crown shading}

The number of trees in which more than half of the crown was shaded by the crown of a neighboring tree in 2008 was 2761 (39.9\% of all stems, Fig. 4); the number was largest for A. sieboldii (1956), P. umbellifera 
232 (301), and B. javanica (105). The most frequent canopy species were E. photiniifolius (793), B. javanica (685),

233 and Celtis boninensis (219).

234

The mean annual diameter growth of understory trees was significantly less than that of canopy trees

235

236

under $A$. sieboldii (Fig. 5). On the other hand, understory individuals of $B$. javanica exhibited superior growth compared with that of native understory tree species, regardless of the canopy tree species (Fig. 6). Although the $\mathrm{CW}$ index was much larger in M. azedarach $(\mathrm{CW}=5.3)$ and C. boninensis (4.9) compared with that of all other species (Fig. 7), the largest values of $\mathrm{CW}$ among dominant species (i.e., those with $\geq 100$ canopy individuals) were for E. photiniifolius (2.2), followed by B. javanica (1.9) and Planchonella obovata var. obovata (1.1). The most frequent dominant species, A. sieboldii, showed a small $\mathrm{CW}$ index $(<0.1)$.

\section{Prediction of invasion by B. javanica}

In the Shimizu plot, B. javanica increased substantially in both the number of stems (176.4\%) and basal area (177.8\%) for the 19-year period (Table A.1). We applied these changes for B. javanica to estimate the coefficients of logistic curves (Fig. 8). The coefficients of the logistic model were $a=36.214$ and $b=0.038$ based on the number of stems, and $a=36.155$ and $b=0.051$ based on the basal area. The model predicted that 
250 in the eastern plot, B. javanica will account for $30 \%$ of the number of stems in 2033 and $30 \%$ of the basal area

251 in 2017. In the eastern plot, B. javanica will account for $30 \%$ of the number of stems in 2087 and $30 \%$ of the

252 basal area in 2057. In the eastern plot, B. javanica will account for $50 \%$ of the number of stems in 2056 and $50 \%$

253 of the basal area in 2034. In the western plot, B. javanica will account for $50 \%$ of the number of stems in 2109

254 and $50 \%$ of the basal area in 2074 .

Discussion

The invasive tree species $B$. javanica showed increased performance relative to native trees after

typhoon 0614 YAGI. The diameter growth rate and survival rate of $B$. javanica were higher than those of other

tree species in the study plots, including native pioneer trees. Given that rapid growth is a strong indicator of

invasiveness (Lamarque et al. 2011), B. javanica showed high invasive ability in the Sekimon area of Haha-jima

Island. In addition, B. javanica showed the most rapid leaf flush after defoliation by the typhoon (Fig. 1d). Since

the size distribution of adult $B$. javanica trees was richest in the smallest size class and the seedlings in the forest

floor was frequent (Abe et al., 2018), its recruitment is presumed to be high. As a result, B. javanica increased

in population size after the typhoon, whereas native tree species decreased in population size. Dominant native

tree species mostly ceased diameter growth for two years while pioneer trees showed larger diameter growth

rate. The negative correlation between diameter growth rate and population growth rate among the dominant 
268 Foster 1992; Wright et al. 2003). However, B. javanica showed exceptional positive population growth despite

269 the rapid diameter growth. This difference may be the result of an inherent vulnerability to invasive species on

270 oceanic islands that exhibit a high percentage endemicity (Berglund et al. 2009; Walsh et al. 2012). Windstorm

271 disturbance usually creates the opportunity for invasive plant species to spread in natural insular forests (Fine

272 2002; Denslow 2003; Lugo 2004; Bellingham et al. 2005; Shimizu 2005). A high number of seedlings of $B$.

273 javanica and two additional alien species, Carica papaya and Morus australis, were observed on the Sekimon

274 forest floor (Abe et al. 2018). This observation suggests that these alien species show high propagule pressure.

275 In particular, seedlings of B. javanica show high photosynthetic plasticity (Kamaluddin and Grace 1992;

276 Yamashita et al. 2000), which can promote their acclimation to a range of light environments and permit a rapid

277 growth response after forest disturbance (Pattison et al. 1998). Therefore, the seedlings of B. javanica are likely

278 to exhibit greater percentage survival than native species after typhoon disturbance. Subsequently, young understory stems of B. javanica grew more rapidly than understory individuals of native tree species regardless of the canopy tree species (Fig. 6).

species is still in an early stage of invasion compared to other forests in the Ogasawara Islands. The number of 
286

287

288

289

290

291

292

$50 \mathrm{~km}$ north of Haha-jima (Hata et al. 2006). Even in the early stage of invasion, the rate of increase of $B$.

javanica in the Sekimon forests has exceeded those of native tree species, even though native species also have increased over the 19 years (Table A.1). During this period, typhoons with a wind speed of more than $20 \mathrm{~m} \mathrm{~s}^{-1}$ struck 12 times and more than $30 \mathrm{~m} \mathrm{~s}^{-1}$ struck four times in the Ogasawara Islands (Table A.2). A preliminary study of the Sekimon forests also reported significant damage to the forest by a severe typhoon in 1983 (Shimizu 1994). Repeated wind-induced disturbance is likely to have assisted the spread of B. javanica in the Sekimon forests.

Regarding crown position, the two dominant tree species, A. sieboldii and P. umbellifera, grew less under a B. javanica crown than those under E. photiniifolius and A. sieboldii crowns, respectively. Given that the defoliation damage caused by typhoon 0614 YAGI had recovered in 2008, the stem growth during the preceding two years included the effects of both typhoon disturbance and later crown shading, which are difficult to distinguish. A lower diameter growth rate under a $B$. javanica crown is partly due to the more rapid recovery of $B$. javanica crowns after the typhoon damage (Fig. 1d). In addition, B. javanica showed a relatively high CW, whereas few native tree species showed a high CW in the Sekimon forests. The dominant species $A$. sieboldii is a sub-canopy tree and develops a narrow crown. The tree species with a wide crown have a relatively deep crown (e.g., Aiba and Kohyama 1997), and its understory would be poor light condition. Accordingly, although we did not measure the difference of light condition, it is assumed that B. javanica, which has a high CW suppress more understory stems than many native trees with low $\mathrm{CW}$. This may be the reason why $P$. umbellifera individuals 
showed superior growth under $A$. sieboldii crowns than under B. javanica crowns. Other native tree species (e.g.,

Machilus boninensis, Melicope grisea var. grisea, $O$. nakaiana, and $P$. umbellifera) also produce narrow crowns

and are likely to have similar effects on understory trees that we may have failed to detect (Fig. 5) because of

the small sample sizes. Although spatiotemporal variation in forest structure caused by wind-induced disturbance

is an important mechanism of tree species coexistence (Kohyama, 1992), invasion by B. javanica that

outcompetes all other canopy tree species, such as E. photiniipholius and P. umbellifera, would homogenize the

various crown-understory relationships and disrupt the stable coexistence mechanism of native tree species. $B$.

javanica showed positive population growth after the typhoon and a high rate of diameter growth in both canopy

and understory individuals compared with those of native species, which would be an important mechanism in

the replacement of native forest by an invasive tree species.

(Yamashita et al., 2003; Tanaka et al., 2010), it is very likely to expand in the Sekimon. For example, Mt.

Kuwanoki in Hahajima Island was the primary mesic forest as Shimon before the war, but after the return from

USA, it changed to the forest dominated by B. javanica (Shimizu, 1988; Toyoda, 2003). It is feared that a similar

II (expansion) of its invasion, based on the results of Webster and Wangen (2009), and eradication will be 
322

323

325

B. javanica would account for 30\% of the basal area by 2017 in the eastern plot and by 2057 in the western plot.

These estimations provide important time limits at which it is possible to eradication all mature individuals at once, in compliance with the guideline. In other forests on Haha-jima Island, B. javanica has become the dominant tree species ( $40 \%$ to $50 \%$ of all individual stems or relative dominance) and has affected plant species diversity (Shimizu 1988; Toyoda and Kawaoka 2005). In addition, this dominance range (30\% to 50\%) corresponds to the stage of most rapid expansion in population size represented by the logistic curve. Therefore, these dominance values are considered to be useful to set a time limit for action to eradicate both empirically and logically. It is of crucial scientific importance that the population growth rate of invasive tree species can be estimated for a primary forest of high conservation value.

\section{Conclusions}

This study presents a typical example of the expansion mechanism and quantitative prediction of the time-limit to eradicate an invasive tree species in an insular primary forest. The differences in diameter growth rates among tree species and the relationships with crown position explained the mechanism by which $B$.

javanica outcompetes and excludes many of the native tree species. Understory individuals of B. javanica grew more rapidly than native tree species and, once reaching the forest canopy, suppressed the growth of native species, resulting in their gradual decline. This pattern of competition also explains how invasive tree species reduce species diversity in natural forests. Prediction by a simple logistic regression model suggested the urgent 
340 need for eradication and will contribute to decision-making to develop an effective conservation strategy

341 (Higgins et al. 2000; Bukley et al. 2003). The short settlement history (about 200 years) of the Ogasawara Islands

342 has allowed the primary forests to survive and retain many endemic endangered plants as in the case of the

343 Sekimon forests (Abe et al. 2018). Since the impacts of alien trees appears with a time-lag, however, the impacts

344 confirmed in this study is likely to be even greater (Downey and Richardson, 2016). Immediate eradication of

345 B. javanica and long-term monitoring are required to prevent further degradation of biodiversity in the

346 Ogasawara Islands.

\section{Acknowledgments}

We thank the staff of the National Forest Division of the Ogasawara General Office and Ministry of

the Environments for granting permission to carry out our field survey. Yoshio Hoshi and Hiromi Umeno helped

with the field surveys. We thank Robert McKenzie, PhD, from Edanz Group (www.edanzediting.com/ac), for

editing a draft of this manuscript.

\section{References}

Abe T, Yasui T, Makino S. 2011. Vegetation status on Nishi-jima Island (Ogasawara) before eradication of alien 
358

359

360

361

362

363

364

365

366

367

368

369

370

371

372

373

374

375

Abe T, Tanaka N, Shimizu Y. 2018. Plant species diversity, community structure and invasion status in insular primary forests on the sekimon uplifted limestone (Ogasawara Islands). Journal of Plant Research 131:10011014

Aiba S, Kohyama T. 1997. Crown architecture and life-history traits of 14 tree species in a warm-temperate rain forest: significance of spatial heterogeneity. Journal of Ecology 85:611-624

Bellard C, Cassey P, Blackburn TM. 2016. Alien species as a driver of recent extinctions. Biology Letters $12: 20150623$

Bellingham PJ, Tanner EVJ, Healey JR. 2005. Hurricane disturbance accelerates invasion by the alien tree Pittosporum undulatum in Jamaican montane rain forests. Journal of Vegetation Science 16:675-684

Berglund H, Järemo J, Bengtsson G. 2009. Endemism predicts intrinsic vulnerability to nonindigenous species on islands. American Naturalist 174:94-101

Binggeli P. 1996. A taxonomic, biogeographical and ecological overview of invasive woody plants. Journal of Vegetation Science 7:121-124

Brown KA, Scatena FN, Gurevitch J. 2006. Effects of an invasive tree on community structure and diversity in a tropical forest in Puerto Rico. Forest Ecology and Management 226:145-152.

Buckley YM, Briese DT, Rees M. 2003. Demography and management of the invasive plant species Hypericum perforatum. II. Construction and use of an individual-based model to predict population dynamics and the effects of management strategies. Journal of Applied Ecology 40:494-507 
376 Chapin III FS, Zavaleta ES, Eviner VT, Naylor RL, Vitousek PM, Reynolds HL, Hooper DU, Lavorel S, Sala

377 OE, Hobbie SE, Mack MC, Díaz S. 2000. Consequences of changing biodiversity. Nature 405:234-242

378 Crooks JA. 2002. Characterizing ecosystem-level consequences of biological invasions: the role of ecosystem

Fukasawa K, Koike F, Tanaka N, Otsu K. 2009. Predicting future invasion of an invasive alien tree in a Japanese

Frappier B, Lee TD, Olson KF, Eckert RT. 2003. Small-scale invasion pattern, spread rate, and lag-phase behavior of Rhamnus fragngula L. Forest Ecology and Management 186:1-6

Downey PO, Richardson DM. 2016. Alien plant invasions and native plant extinctions: a six-threshold frameworks. AoB Plants 8:plw047

Fine PVA. 2002. The invisibility of tropical forests by exotic plants. Journal of Tropical Ecology 18:687-705

Fukawa K, Koike F, Tanak $\mathrm{N}$ Otsu K. 2009. Predicting future invasion of an invasive alien tree in a Japanese oceanic island by process-based statistical models using recent distribution maps. Ecological Research 
394

395

396 regime shifts: identifying high-priority invaders that alter feedback relationships. Diversity and Distributions 20:733-744

Grubb PJ. 1977. The maintenance of species-richness in plant communities: the importance of the regeneration niche. Biological Reviews 52:107-145

Hata K, Suzuki J, Kachi N, Yamamura Y. 2006. A 19-year study of the dynamics of an invasive alien tree, Bischofia javanica, on a subtropical oceanic island. Pacific Science 60:455-470

Higgins SI, Richardson DM, Cowling RM. 2000. Using a dynamic landscape model for planning the management of alien plant invasions. Ecological Applications 10:1833-1848

Hubbell SP, Foster RB. 1992. Short-term dynamics of a neotropical forest: why ecological research matters to tropical conservation and management. Oikos 63:48-61

Japan Meteorological Agency. 2018. Past typhoon information. Available at https://www.data.jma.go.jp/fcd/yoho/typhoon/index.html (Accessed 20 October 2018).

Kamaluddin M, Grace J. 1992. Photoinhibition and light acclimation in seedlings of Bischofia javanica, a tropical forest tree from Asia. Annals of Botany 69:47-52

Kier G, Kreft H, Lee TM, Jetz W, Ibisch PL, Nowicki C, Mutke J, Barthlott W. 2009. A global assessment of endemism and species richness across island and mainland regions. Proceedings of the National Academy of Sciences USA 106:9322-9327 
412 growth and recruitment in canopy gaps. Journal of Torrey Botanical Society 127:307-315

413 Lamarque LJ, Delzon S, Lortie CJ. 2011. Tree invasions: a comparative test of the dominant hypotheses and

414 functional traits. Biological Invasions 13:1969-1989

415 Lavergne C, Rameau JC, Figier J. 1999. The invasive woody weed Ligustrum robustum subsp. walkeri threatens native forests on La Réunion. Biological Invasions 1:377-392

417 Lepš J, Novotný V, Lukaš Š, Molem K, Isua B, Boen W, Kutil R, Augua J, Kasbal M, Manumbor M, Hiuk S. Applied Vegetation Science 5:255-262

Lin YC, Comita LS, Johnson DJ, Chen MR, Wu SH. 2017. Biotic vs abiotic drivers of seedling persistence in a tropical karst forest. Journal of Vegetation Science 28:206-217

Lockwood JL, Hoopes MF, Marchetti MP. 2007. Invasion ecology. Malden: Blackwell.

Lonsdale WM. 1999. Global patterns of plant invasions and the concept of invasibility. Ecology 89:1522-1536

Losos EC, Leigh Jr EG. 2004. Tropical forest diversity and dynamism. Chicago: University of Chicago Press.

Mack RN, Simberloff D, Lonsdale WM, Evans H, Clout M, Bazzaz FA. 2000. Biotic invasions: Causes, epidemiology, global consequences, and control. Ecological Applications 10:689-710 
Martin PH, Camham CD, Marks PL. 2009 Why forests appear resistant to exotic plant invasions: intentional

$7: 142-149$

Medeiros AC, Loope LL, Conant P, McElvaney S. 1997. Status, ecology, and management of the invasive plant, 48:23-36

Meyer JY, Florence J. 1996. Tahiti's native flora endangered by the invasion of Miconia calvescens DC.

(Melastomataceae). Journal of Biogeography 23:775-781

Meyer JY, Lavergne C. 2004. Beautés fatales: Acanthaceae species as invasive alien plants on tropical Indoecosystem. Biological Invasions 17:1817-1832

Mueller-Dombois D. 2008. Pacific island forests: Successionally impoverished and now threatened to be

Okamoto T, Hori N, Urata K, Komatsu Y. 1995. Soils of karst areas in Chichi-jima Island and Haha-jima Island 
448 Pattison RR, Goldstein G, Ares A. 1998. Growth, biomass allocation and photosynthesis of invasive and native

$449 \quad$ Hawaiian rainforest species. Oecologia 117:449-459

450 Pimentel DL, Lach L, Zuniga R, Morisson D. 2000. Environmental and economic costs of nonindigenous species

$451 \quad$ in the United States. Bioscience 50:53-65

452 Potgieter LJ, Wilson JRU, Strasberg D, Richardson DM. 2014. Casuarina invasion alters primary succession on

453 lava flows on La Réunion Island. Biotropica 46:268-275

454 Pyšek P, Richardson DM. 2006. The biogeography of naturalization in alien plants. Journal of Biogeography

$33: 2040-2050$

Radosevich SR, Stubbs MM, Ghersa CM. 2003. Plant invasions: process and patterns. Weed Science 51:254-

R Core Team. 2016. R: A language and environment for statistical computing. R Foundation for Statistical

Richardson DM, Hui C, Nuñez MA, Pauchard A. 2014. Tree invasions: patterns, processes, challenges and opportunities. Biological Invasions 16:473-481

Richardson DM, Rejmánek M. 2011. Trees and shrubs as invasive alien species - a global review. Diversity and

Sakai AK, Allendorf FW, Holt JS, Lodge DM, Molofsky J, With KA, Baughman S, Cabin RJ, Cohen JE, 
466

467

468

469

470

471

472

473

475

476

477

478

479

480

481

482

483

of invasive species. Annual Review of Ecology and Systematics 32:305-332

Sax DF, Gaines SD, Brown JH. 2002. Species invasions exceed extinctions on islands worldwide: A comparative study of plants and birds. America Naturalist 160:766-783

Shimizu Y. 1988. Vegetation and invasion by Bischofia javanica in Mt. Kuwanoki, Hahajima in the Ogasawara Islands. Regional Views 1:31-46 (in Japanese)

Shimizu Y. 1994. Regeneration of mesic forest at Sekimon, Hahajima in the Bonin (Ogasawara) Islands with reference to disturbance of the forest by the Typhoon No.17. Regional Views 7:3-32 (in Japanese)

Shimizu Y. 2003. The nature of Ogasawara and its conservation. Global Environmental Research 7:3-14

Tanaka N, Fukasawa K, Otsu K, Noguchi E, Koike F. 2010. Eradication of the invasive tree species Bischofia javanica and restoration of native forests in the Ogasawara Islands. In: Kawakami K, Okochi I, eds. Restoring the oceanic island ecosystem: Impact and management of invasive alien species in the Bonin Island. Tokyo: Springer, 161-171.

Toyoda T. 2003. Flora of the Bonin Islands, 2nd ed. Kamakura: Aboc-sha Co. Ltd. (in Japanese)

Toyoda T, Kawaoka Y. 2005. Decline of native plants accompany with crown dominance of alien Bischofia javanica. Ogasawara Kenkyu Nenpo 28:73-85 (in Japanese)

Toyoshima H. 1938. On the vegetation and the useful tropical plants in the Ogasawara Islands. Bulletin of the Imperial Forestry Experimental Station 36:1-251

Vitousek PM, Walker LR. 1989. Biological invasion by Myrica faya in Hawai'i: plant demography, nitrogen 
Walsh JC, Venter O, Watson JEM, Fuller RA, Blackburn TM, Possingham HP. 2012. Exotic species richness Biogeography 21:841-850

Wangen SR, Webster CR. 2006. Potential for multiple lag phases during biotic invasions: reconstructing an invasion of the exotic tree Acer platanoides. Journal of Applied Ecology 43:258-268

Yamashita N, Ishida A, Kushima H, Tanaka N. 2000. Acclimation to sudden increase in light favoring an platanoides. Forest Ecology and Management 208:85-99

Wiser SK, Drake DR, Burrows LE, Sykes WR. 2002. The potential for long-term persistence of forest fragments on Tongatapu, a large island in western Polynesia. Journal of Biogeography 29:767-787

Wright SJ, Muller-Landau HC, Condit R, Hubbell SP. 2003. Gap-dependent recruitment, realized vital rates, and size distribution of tropical trees. Ecology 84:3174-3185 
502 native trees of subtropical Pacific islands. Journal of Vegetation Science 14:15-24

503 Yonekura K, Murata J. 2012. An enumeration of the vascular plants of Japan: a list of the Latin and Japanese

$504 \quad$ names of the vascular plants indigenous and naturalized in Japan arranged in the order of phylogeny-based

505 system. Tokyo: Hokuryukan Co., Ltd. (in Japanese)

506 Yoshida K, Oka S. 2000. Ecological characteristics of Morus boninensis reconstructed from its remaining stumps

507 in the Sekimon Region of Haha-jima Island, Ogasawara (Bonin) Islands, northwestern Pacific. Japanese

$508 \quad$ Journal of Historical Botany 9:21-28 (in Japanese) 
511 Fig. 1. Photographs showing the situation of the Sekimon forests after the typhoon. (a) View of the mesic forests

512 on the Sekimon uplifted limestone on 4 October 2006. The southern part of the uplift collapsed in a landslide in 1997. (b) Defoliation of canopy crowns by typhoon 0614 YAGI (22 November 2006). (c) Regeneration of Sambucus chinensis var. formosana on the sunny forest floor after the typhoon (17 April 2007). (d) Rapid umbellifera and Ardisia sieboldii (22 November 2006).

Fig. 2. Population growth rates (individuals of $\mathrm{DBH} \geq 10 \mathrm{~cm}$ ) of the most frequent tree species between 2006

Fig. 3. Annual diameter growth rate from 2006 to 2008. The stem diameter was measured at breast height. The thick line in the center of the boxplot shows the median value of the data. The top of the box represents the third quartile and the bottom of the box represents the first quartile. Circles represent outliers. Abbreviations 
Fig. 4. Frequency of crown positions in the 4 ha survey area in 2008. "Covered by" is the total number of understory stems $(\mathrm{DBH} \geq 10 \mathrm{~cm})$ that the species covered. "Be covered" is the number of understory stems name are defined in Table 1.

Fig. 6. Annual diameter growth rate under the crown of the six most frequent tree species. Canopy species are species name are defined in Table 1. height. Values within parentheses represent the number of canopy individuals. Bars labeled with different letters differ significantly $(P<0.05$, Tukey-Kramer test). Error bars represent the SE. Abbreviations of

Fig. 5. Annual diameter growth rate in the six most frequent tree species under canopy trees. Understory species are (a) Bija, (b) Plob, (c) Pium, (d) Elph, (e) Arsi and (f) Ocna. The stem diameter was measured at breast (a) Bija, (b) Plob, (c) Pium, (d), Cebo, (e) Elph and (f) Arsi. The stem diameter was measured at breast height. Values within parentheses represent the number of understory stems. Bars labeled with different letters differ significantly $(P<0.05$, Tukey-Kramer test). Error bars represent the SE. Abbreviations of 
547 Fig. 7. Crown width index values for the tree species in the survey area. Abbreviations of species name are $548 \quad$ defined in Table 1.

Fig. 8. Predictions of the increase in Bischofia javanica population size. Estimation of population size is based regressions based on data recorded in 1987 and 2006 in the Shimizu plot (filled circle). "West" and "East" refer to the two plots in Fig. A.1.

Table 1 Abbreviations for tree species names. Species order is based on APG III (Yonekura and Murata, 2012).

Table 2 Numbers of trees damaged by typhoon 0614 YAGI. "Uprooted" includes inclined individuals with at least half of the root system exposed. Values of the number of damaged stems are "the number of damaged stems including dead stems" / "the number of dead stems" in 1 ha area. E, Endemic to the Ogasawara Islands; I, indigenous; A, alien for the Ogasawara Islands. Typhoon YAGI was situated closest to Hahajima Island on 22 September 2006 and the survey was conducted in November 2006. Abbreviations of species name are defined in Table 1.

Fig. A.1 Location of study site. (a) Haha-jima Island and the Sekimon forests on uplifted limestone and (b) the 
565

566

567 census plots in the Sekimon forests. Crosshatched rectangles are the two 2-ha plots surveyed in the present study; the gray-shaded rectangle at the southern edge of the western plot represents the plot studied by Shimizu (1994), of which the southernmost part was lost to a landslide. the irregular gray-shaded area at the northeastern corner of the eastern plot represents a former Bischofia javanica plantation.

Table A.1 Changes in the number of stems $(N)$ and basal area (BA) of trees (DBH $\geq 10 \mathrm{~cm})$ between 1987 and 2006. The 1987 values are from the Shimizu (1994) and the 2006 values are collected by the present study within the former Shimizu plot $(60 \mathrm{~m} \times 50 \mathrm{~m})$. Species are listed in descending order of BA in 1987 . Numbers within parentheses after the BA values in 2006 represent the species order based on the BA in 2006. Only Bischofia javanica is an alien species. Species order is based on descending order of BA in 1987.

Table A.2 Typhoons for which a wind velocity of more than $20 \mathrm{~m} \mathrm{~s}^{-1}$ was recorded in the Ogasawara Islands between 1987 and 2006. The data is from the Chichi-jima Weather Station (Japan Meteorological Agency, 2018). 


\section{Table $\mathbf{1}$ (on next page)}

Abbreviations for tree species names.

Species order is based on APG III (Yonekura and Murata, 2012). 


\begin{tabular}{|c|c|c|}
\hline Family & Species & $\begin{array}{c}\text { Species } \\
\text { abbr. }\end{array}$ \\
\hline \multirow[t]{2}{*}{ Cyatheaceae } & Cyathea mertensiana & Cyme \\
\hline & C. spinulosa & Cysp \\
\hline \multirow[t]{5}{*}{ Lauraceae } & Cinnamomum pseudopedunculatum & Cips \\
\hline & Machilus boninensis & Mabo \\
\hline & M. kobu & Mako \\
\hline & Neolitsea sericea var. aurata & Nese \\
\hline & N. boninensis & Nebo \\
\hline Pandanaceae & Pandanus boninensis & Pabo \\
\hline Arecaceae & Livistona boninensis & Libo \\
\hline Rosaceae & Rhaphiolepis indica var. umbellata & Rhin \\
\hline \multirow[t]{2}{*}{ Cannabaceae } & Celtis boninensis & Cebo \\
\hline & Trema orientalis & Tror \\
\hline \multirow[t]{4}{*}{ Moraceae } & Ficus boninsimae & Fibo \\
\hline & F. iidana & Fiii \\
\hline & Morus australis & Moau \\
\hline & M. boninensis & Mobo \\
\hline Elaeocarpaceae & Elaeocarpus photiniifolius & Elph \\
\hline Euphorbiaceae & Claoxylon centinarium & Clce \\
\hline Phyllanthaceae & Bischofia javanica & Bija \\
\hline Putranjivaceae & Drypetes integerrima & Drin \\
\hline Myrtaceae & Syzygium cleyerifolium & Sycl \\
\hline \multirow[t]{2}{*}{ Rutaceae } & Melicope grisea var. grisea & Megr \\
\hline & Zanthoxylum ailanthoides var. inerme & Zaai \\
\hline Meliaceae & Melia azedarach & Meaz \\
\hline Malvaceae & Hibiscus glaber & Higl \\
\hline Caricaceae & Carica papaya & Capa \\
\hline Nyctaginaceae & Pisonia umbellifera & Pium \\
\hline Sapotaceae & Planchonella obovata var. obovata & Plob \\
\hline Primulaceae & Ardisia sieboldii & Arsi \\
\hline \multirow[t]{2}{*}{ Rubiaceae } & Gardenia boninensis & Grbo \\
\hline & Psychotria homalosperma & Psho \\
\hline Loganiaceae & Geniostoma glabrum & Gegl \\
\hline Apocynaceae & Ochrosia nakaiana & Ocna \\
\hline
\end{tabular}




$\begin{array}{llc}\text { Oleaceae } & \text { Ligustrum micranthum } & \text { Limi } \\ \text { Lamiaceae } & \text { Callicarpa subpubescens } & \text { Casu } \\ \text { Aquifoliaceae } & \text { Ilex mertensii var. beechyi } & \text { Ilmb } \\ & \text { I. mertensii var. mertensii } & \text { Ilmm }\end{array}$

1 


\section{Table 2 (on next page)}

Numbers of trees damaged by typhoon 0614 YAGI.

"Uprooted" includes inclined individuals with at least half of the root system exposed. Values of the number of damaged stems are "the number of damaged stems including dead stems" / "the number of dead stems" in 1 ha area. E, Endemic to the Ogasawara Islands; I, indigenous; A, alien for the Ogasawara Islands. Typhoon YAGI was situated closest to Hahajima Island on 22 September 2006 and the survey was conducted in November 2006. Abbreviations of species name are defined in Table 1. 


\begin{tabular}{|c|c|c|c|c|c|c|}
\hline \multirow[b]{2}{*}{ Species } & \multirow[b]{2}{*}{ Origin } & \multirow[b]{2}{*}{$\mathrm{N}$} & \multicolumn{4}{|c|}{ The number of damaged stems } \\
\hline & & & Defoliated & Snapped & Uprooted & Trapped \\
\hline Cyme & $E$ & 28 & $28 / 1$ & $4 / 3$ & $2 / 2$ & $0 / 0$ \\
\hline Cysp & $\mathrm{E}$ & 8 & $8 / 1$ & $0 / 0$ & $0 / 0$ & $0 / 0$ \\
\hline Mabo & $E$ & 75 & $75 / 5$ & $11 / 2$ & $2 / 0$ & $0 / 0$ \\
\hline Mako & $E$ & 8 & $8 / 0$ & $3 / 0$ & $0 / 0$ & $0 / 0$ \\
\hline Rhin & I & 2 & $2 / 0$ & $0 / 0$ & $0 / 0$ & $0 / 0$ \\
\hline Cebo & $E$ & 23 & $23 / 0$ & $0 / 0$ & $0 / 0$ & $0 / 0$ \\
\hline Tror & I & 3 & $3 / 1$ & $0 / 0$ & $0 / 0$ & $0 / 0$ \\
\hline Fibo & $E$ & 51 & $51 / 3$ & $1 / 0$ & $4 / 3$ & $0 / 0$ \\
\hline Moau & $A$ & 2 & $2 / 0$ & $0 / 0$ & $0 / 0$ & $0 / 0$ \\
\hline Elph & $E$ & 208 & $208 / 12$ & $20 / 5$ & $7 / 1$ & $1 / 0$ \\
\hline Bija & $A$ & 54 & $54 / 1$ & $3 / 0$ & $4 / 0$ & $0 / 0$ \\
\hline Sycl & $E$ & 12 & $12 / 0$ & $1 / 0$ & $0 / 0$ & $0 / 0$ \\
\hline Megr & $E$ & 96 & $96 / 8$ & $3 / 2$ & $0 / 0$ & $0 / 0$ \\
\hline Zaai & $E$ & 6 & $6 / 1$ & $0 / 0$ & $0 / 0$ & $0 / 0$ \\
\hline Meaz & I & 1 & $1 / 0$ & $0 / 0$ & $0 / 0$ & $0 / 0$ \\
\hline Higl & E & 27 & $27 / 0$ & $3 / 1$ & $4 / 1$ & $0 / 0$ \\
\hline Pium & I & 56 & $56 / 0$ & $2 / 0$ & $2 / 0$ & $0 / 0$ \\
\hline Plob & I & 81 & $81 / 2$ & $3 / 1$ & $9 / 1$ & $1 / 0$ \\
\hline Arsi & I & 1985 & $1985 / 149$ & $132 / 35$ & $34 / 19$ & $3 / 0$ \\
\hline Grbo & $E$ & 1 & $1 / 0$ & $0 / 0$ & $0 / 0$ & $0 / 0$ \\
\hline Psho & $E$ & 28 & $28 / 4$ & $3 / 1$ & $2 / 1$ & $0 / 0$ \\
\hline Ocna & $E$ & 4 & $4 / 2$ & $0 / 0$ & $0 / 0$ & $0 / 0$ \\
\hline Limi & $E$ & 1 & $1 / 0$ & $0 / 0$ & $0 / 0$ & $0 / 0$ \\
\hline Casu & $E$ & 5 & $5 / 0$ & $1 / 0$ & $2 / 1$ & $0 / 0$ \\
\hline Total & & 2765 & $2675 / 190$ & $190 / 50$ & $72 / 29$ & $5 / 0$ \\
\hline
\end{tabular}




\section{Figure 1}

Photographs showing the situation of the Sekimon forests after the typhoon.

(a) View of the mesic forests on the Sekimon uplifted limestone on 4 October 2006. The southern part of the uplift collapsed in a landslide in 1997. (b) Defoliation of canopy crowns by typhoon 0614 YAGI (22 November 2006). (c) Regeneration of Sambucus chinensis var. formosana on the sunny forest floor after the typhoon (17 April 2007). (d) Rapid flushing of Bischofia javanica after the typhoon damage (22 November 2006). (e) Defoliated crowns of Pisonia umbellifera and Ardisia sieboldii (22 November 2006). 


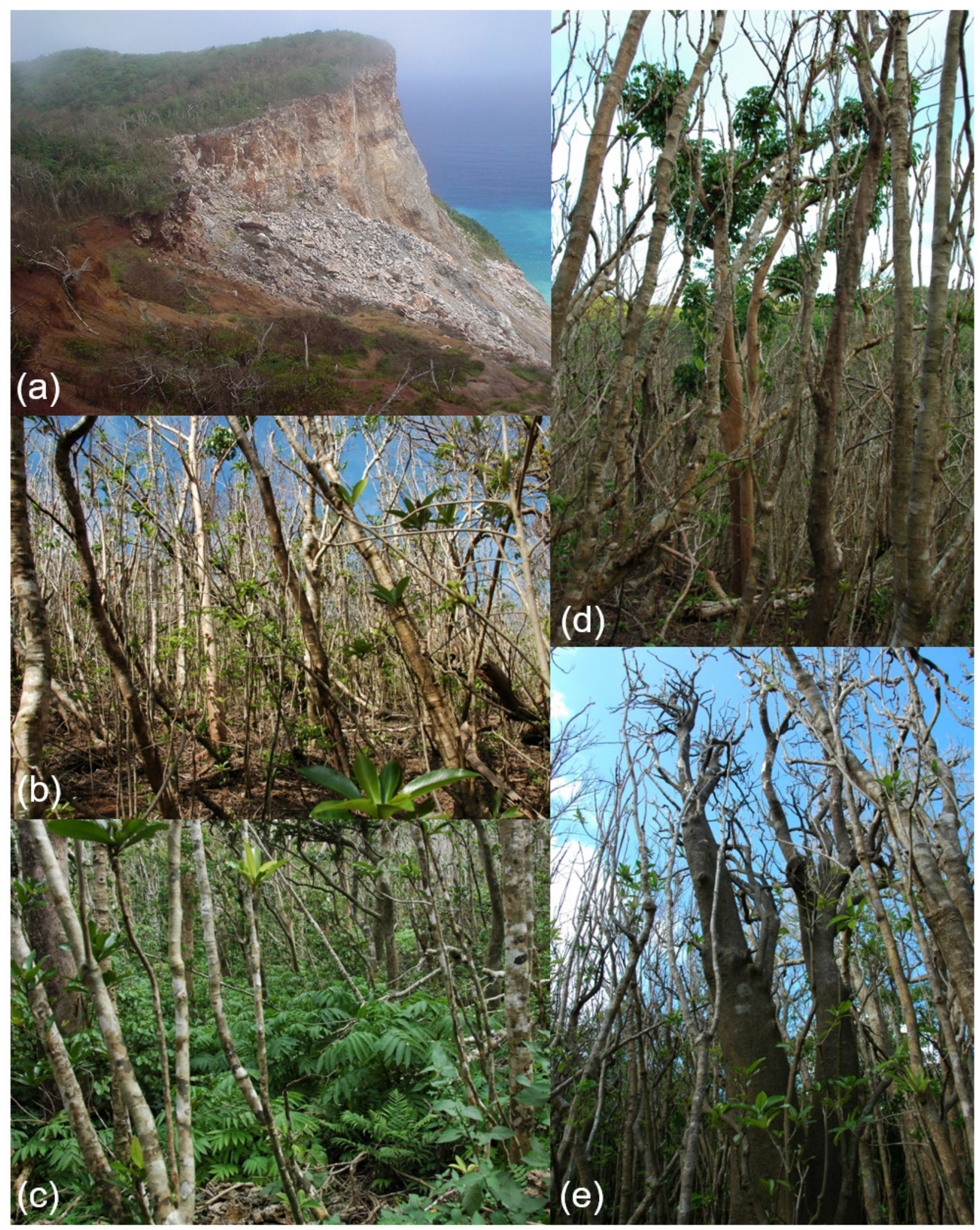




\section{Figure 2}

Population growth rates (individuals of $\mathrm{DBH} \geq 10 \mathrm{~cm}$ ) of the most frequent tree species between 2006 and 2008.

Values within parentheses after the species names represent the number of stems within the survey area (4 ha) in 2006. The significant differences of the proportion of dead and recruited stems between native species and $B$. javanica are shown at the top, respectively. In the tree species with significant difference, recruitments were all less than that of $B$. javanica and deaths were all more than that of $B$. javanica. ***: $p<0.001, * *: p<0.01, *: p<0.05$. Abbreviations for species names are defined in Table 1.

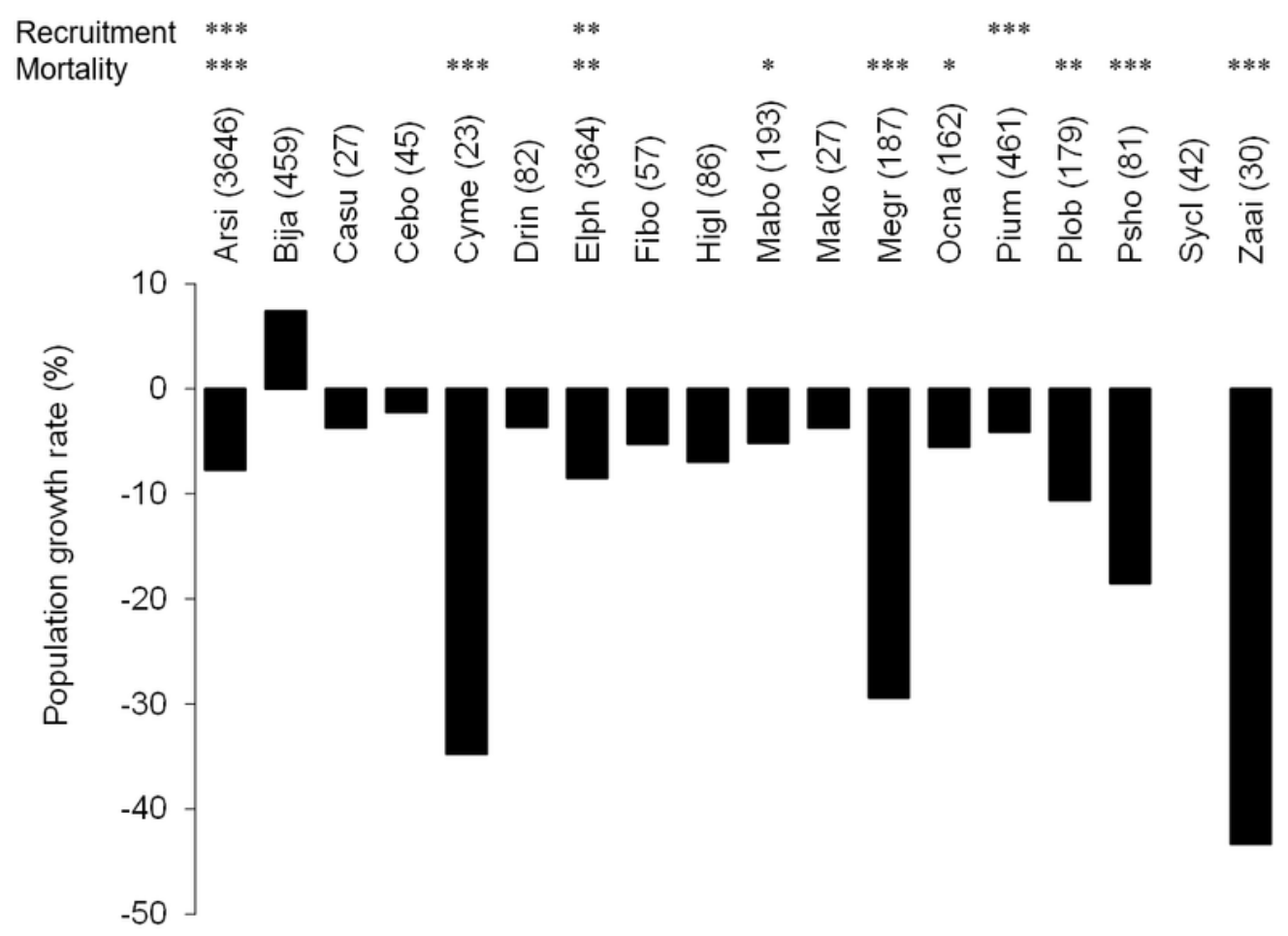




\section{Figure 3}

Annual diameter growth rate from 2006 to 2008.

The thick line in the center of the boxplot shows the median value of the data. The top of the box represents the third quartile and the bottom of the box represents the first quartile.

Circles represent outliers. Abbreviations of species name are defined in Table 1. 


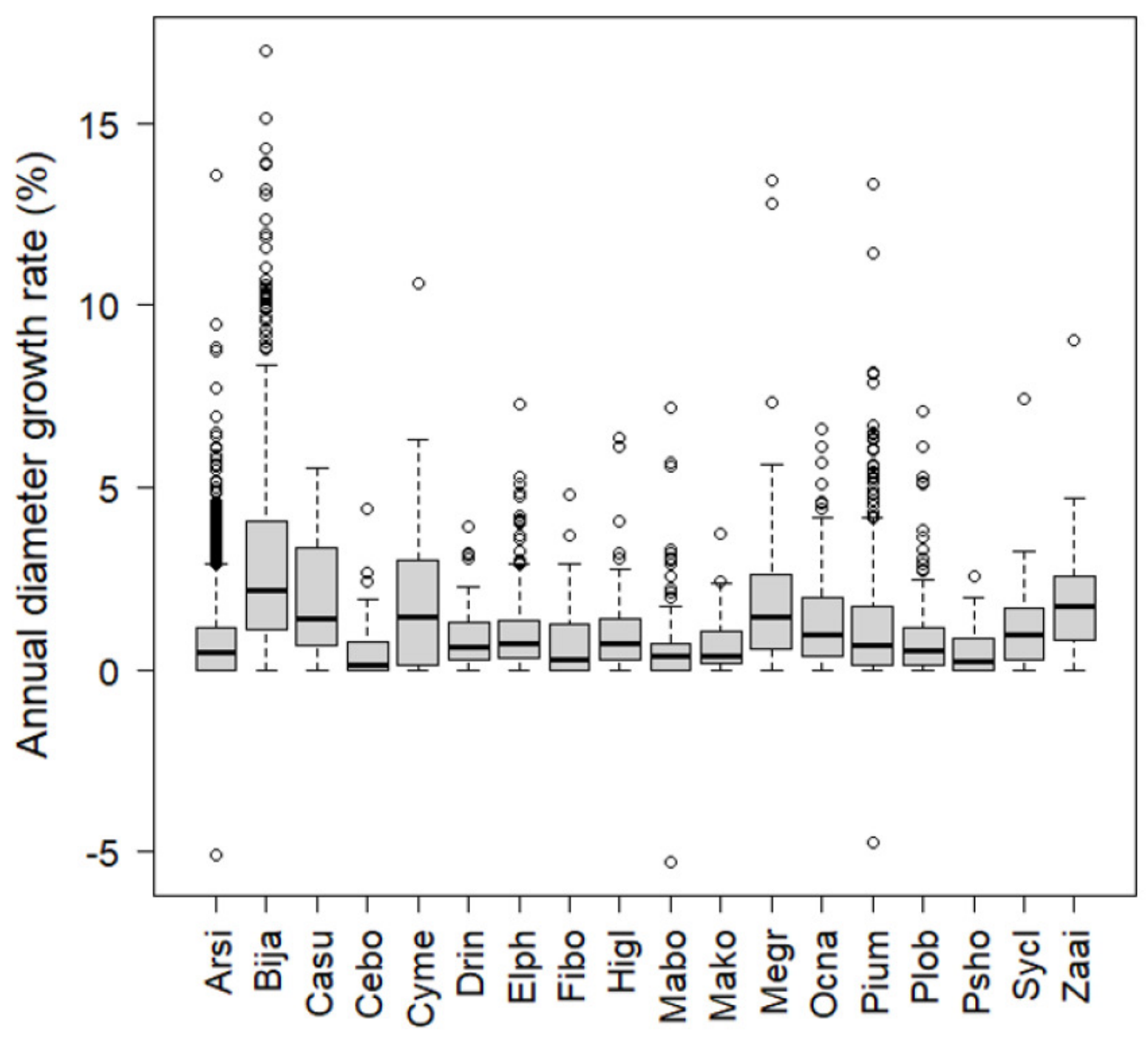


Figure 4

Frequency of crown positions in the 4 ha survey area in 2008.

"Covered by" is the total number of understory stems (DBH $\geq 10 \mathrm{~cm}$ ) that the species

covered. "Be covered" is the number of understory stems of the species that the crown is covered by other trees, including conspecifics. Abbreviations of species name are defined in Table 1.

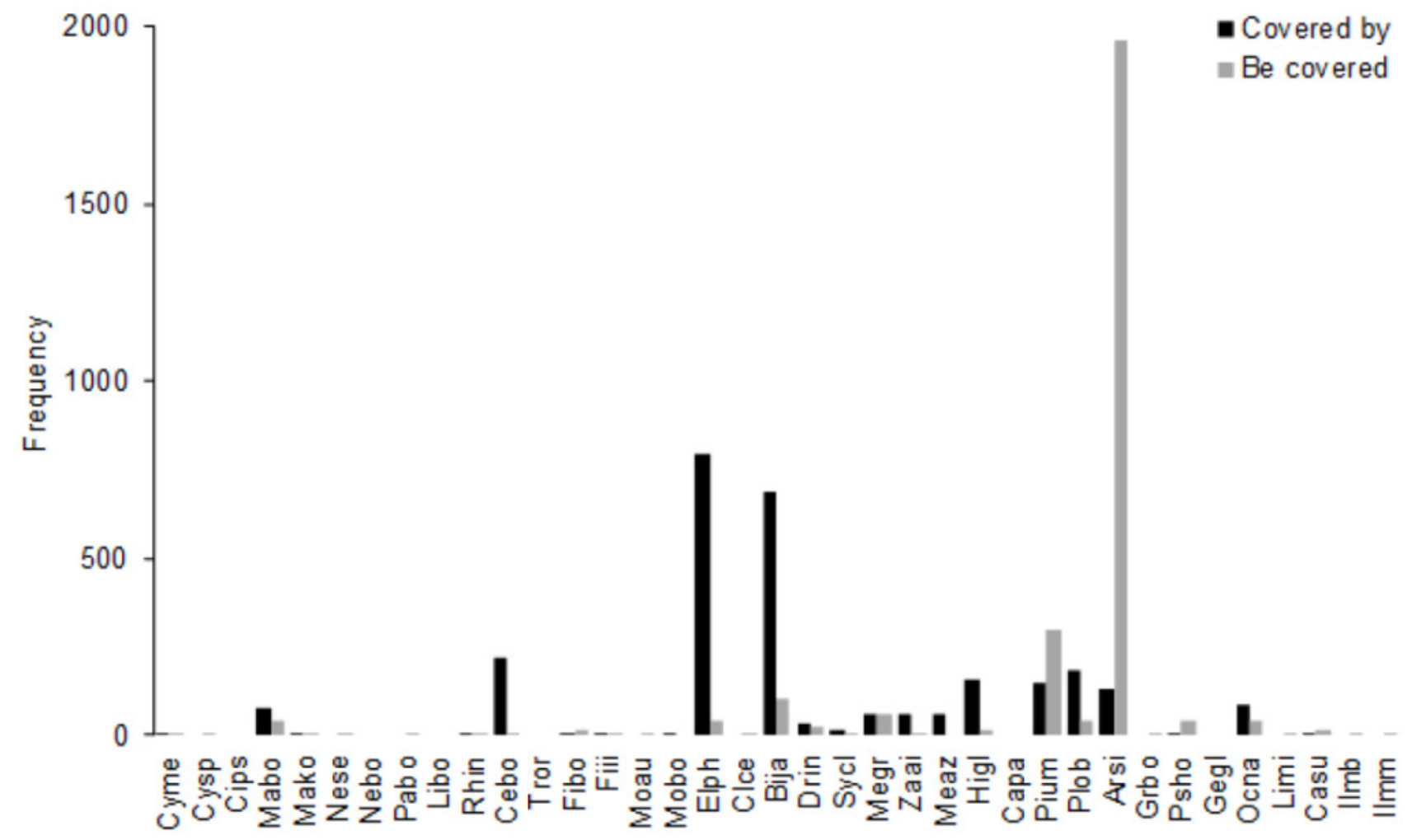




\section{Figure 5}

Annual diameter growth rate in the six most frequent tree species under canopy trees.

Understory species are (a) Bija, (b) Plob, (c) Pium, (d) Elph, (e) Arsi and (f) Ocna. The stem diameter was measured at breast height. Values within parentheses represent the number of canopy individuals. Bars labeled with different letters differ significantly $(P<0.05$, Tukey-Kramer test). Error bars represent the SE. Abbreviations of species name are defined in Table 1. 


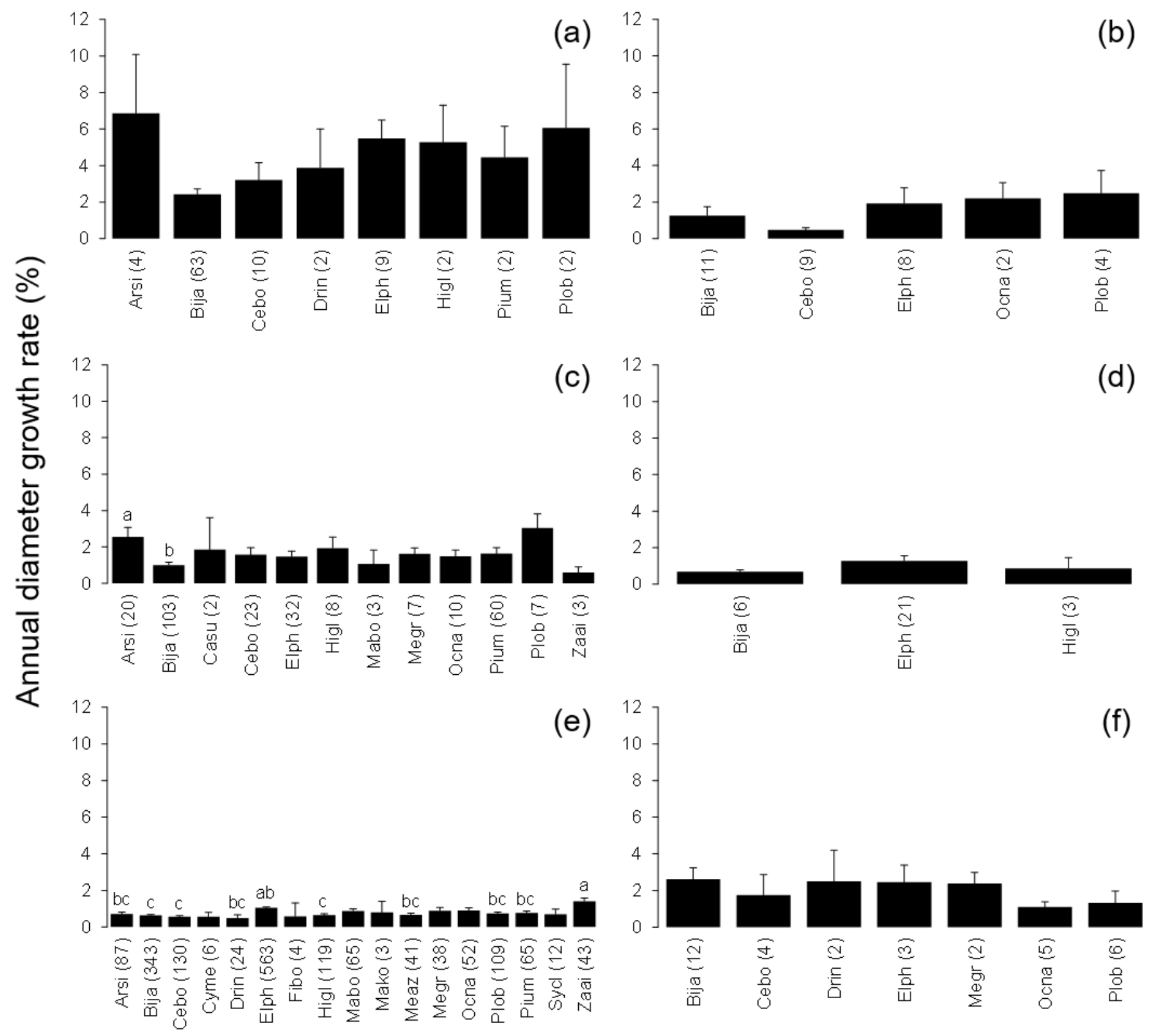

Canopy species 


\section{Figure 6}

Annual diameter growth rate of stem diameter under the crown of the six most frequent tree species.

Canopy species are (a) Bija, (b) Plob, (c) Pium, (d), Cebo, (e) Elph and (f) Arsi. The stem diameter was measured at breast height. Values within parentheses represent the number of understory stems. Bars labeled with different letters differ significantly $(P<0.05$, Tukey-Kramer test). Error bars represent the SE. Abbreviations of species name are defined in Table 1. 


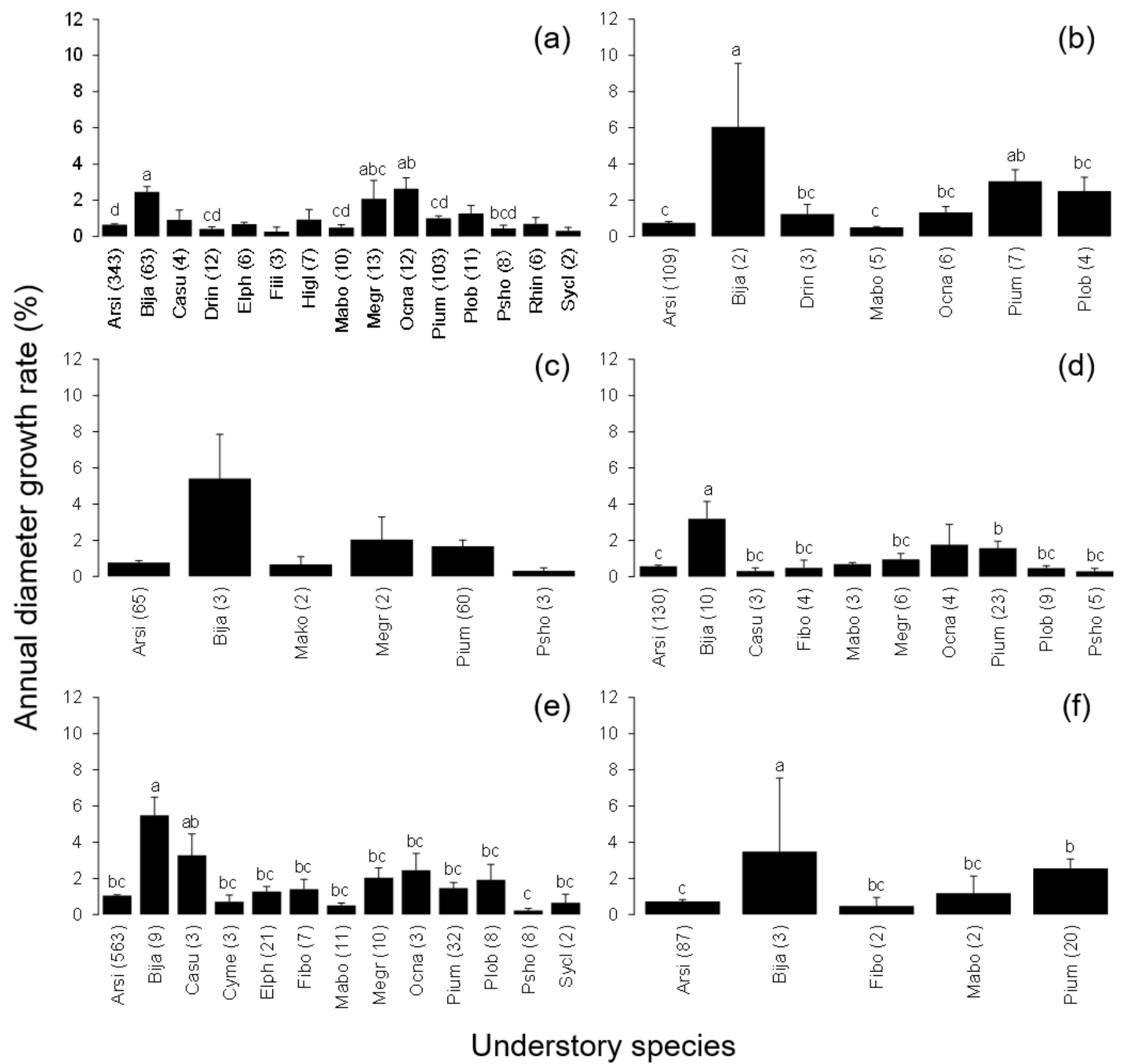


Figure 7

Crown width index values for the tree species in the survey area.

Abbreviations of species name are defined in Table 1.

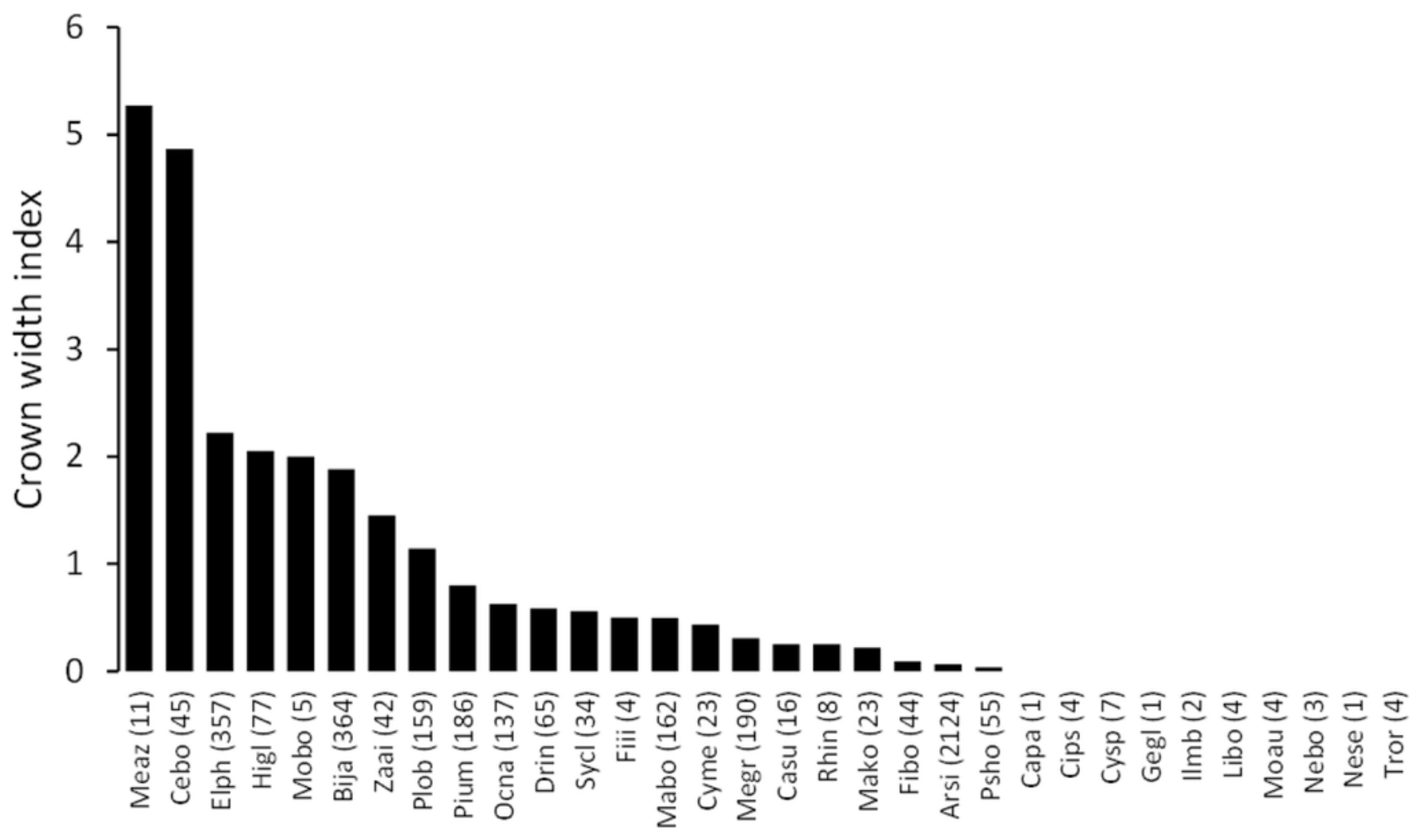


Figure 8

Predictions of the increase in Bischofia javanica population size.

Estimation of population size is based on (a) the number of stems $(N)$ and (b) the total basal area (BA). Data points were predicted by logistic regressions based on data recorded in 1987 and 2006 in the Shimizu plot (filled circle). "West" and "East" refer to the two plots in Fig. A.1. 

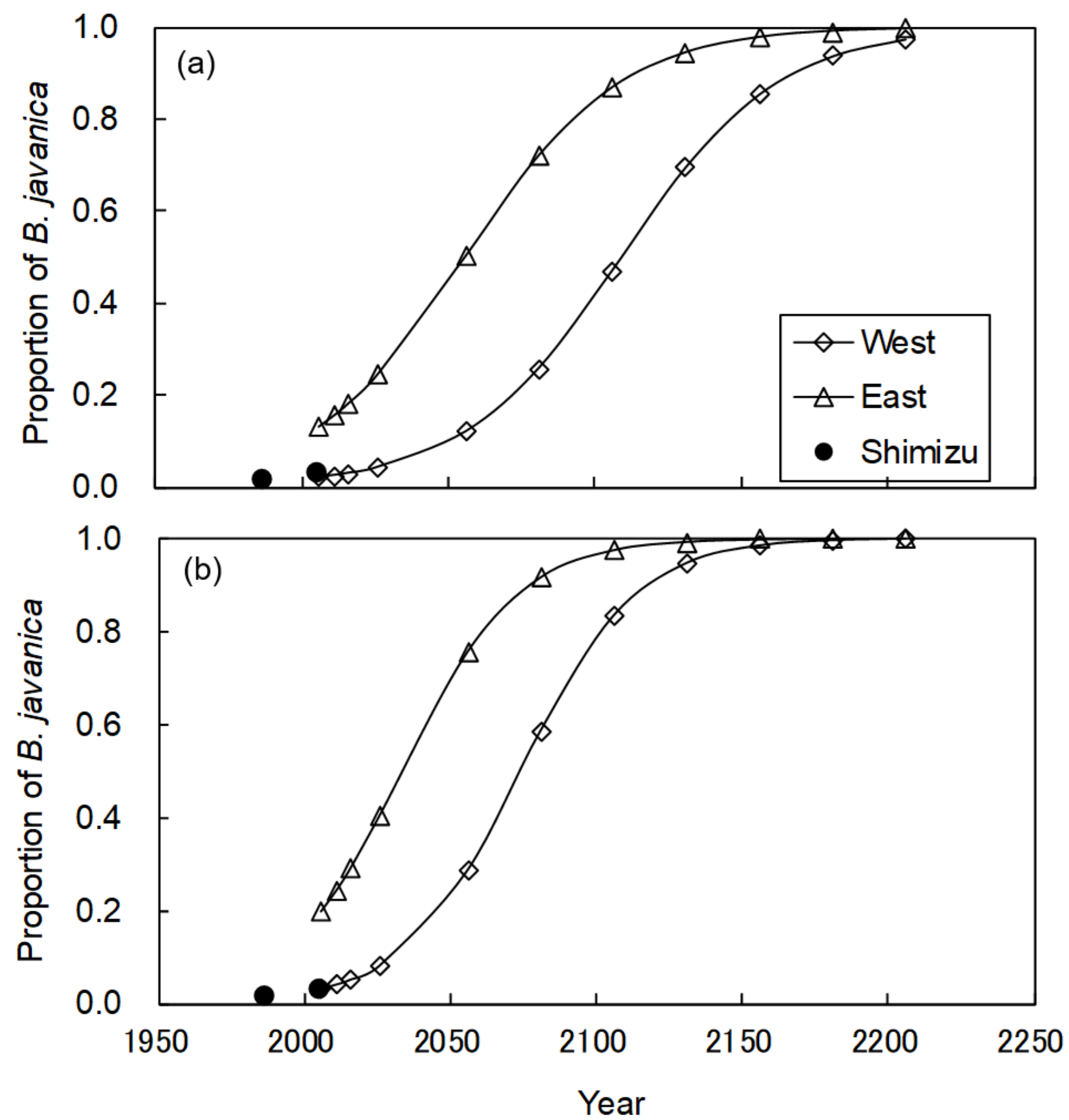